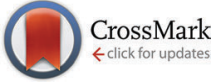

Cite this: Chem. Commun., 2015, 51, 10949

Received 21st February 2015, Accepted 28th May 2015

DOI: $10.1039 / \mathrm{c} 5 \mathrm{cc} 01578 \mathrm{~b}$

www.rsc.org/chemcomm

\section{Heterobimetallic complexes with redox-active mesoionic carbenes as metalloligands: electrochemical properties, electronic structures and catalysis $\uparrow$}

\author{
Lara Hettmanczyk, Sinja Manck, Carolin Hoyer, Stephan Hohloch and \\ Biprajit Sarkar*
}

\begin{abstract}
A mesoionic carbene with a ferrocene backbone is used as a metalloligand to generate the first example of their $\mathrm{Fe}-\mathrm{Au}$ heterobimetallic complexes. The details of geometric and electronic structures in different redox states and preliminary catalytic results are presented.
\end{abstract}

The concept of using metalloligands is useful for generating multinuclear metal complexes. ${ }^{1}$ In this regard, the use of a ferrocene unit in the metalloligand backbone has been highly successful as epitomized by the widely popular metalloligand diphenylphosphino ferrocene (dppf). ${ }^{2}$ Metalloligands such as dppf provide an additional redox-handle that can be utilized "on-demand". The ferrocene unit has also been combined with $\mathrm{N}$-heterocyclic carbenes (NHCs), and metal complexes of such metalloligands are useful for investigating redox properties and as redox-switchable catalysts. ${ }^{3}$ NHCs in general are extremely important ligands in homogeneous catalysis, ${ }^{4}$ and the relatively new types of triazolylidene based mesoionic carbenes (MICs) are fast becoming important ligand classes in their own right. ${ }^{5}$ Most work in this field has concentrated on mononuclear complexes, ${ }^{5}$ with examples of multinuclear complexes being rare. ${ }^{6}$ Almost all of these multinuclear complexes contain only one type of metal center. In the following text, we present a synthetic route to generate new kinds of heterobimetallic complexes based on MIC metalloligands that have additional redox-active ferrocene units in the backbone. We also report on their electrochemical properties, geometric and electronic structures and redox-induced catalysis.

The reaction of ((trimethylsilyl)ethynyl)ferrocene with the appropriate organic azide under typical $\mathrm{Cu}(\mathrm{I})$ catalyzed azide-alkyne cycloaddition (CuAAC) reaction conditions resulted in the formation of the corresponding ferrocenyl-triazoles $(\mathbf{1 a}, \mathbf{1 b} \text {, Scheme } 1)^{7}$

Institut für Chemie und Biochemie, Freie Universität Berlin, Fabeckstraße 34-36, D-14195, Berlin, Germany. E-mail: biprajit.sarkar@fu-berlin.de; Tel: +493083850919 $\dagger$ Electronic supplementary information (ESI) available: The details of synthesis, X-ray crystallography, electrochemistry, spectroelectrochemistry and DFT calculations. CCDC 965899, 965900, 965895, 1015508, 1022581 and 1022582. For ESI and crystallographic data in CIF or other electronic format see DOI: 10.1039/c5cc01578b

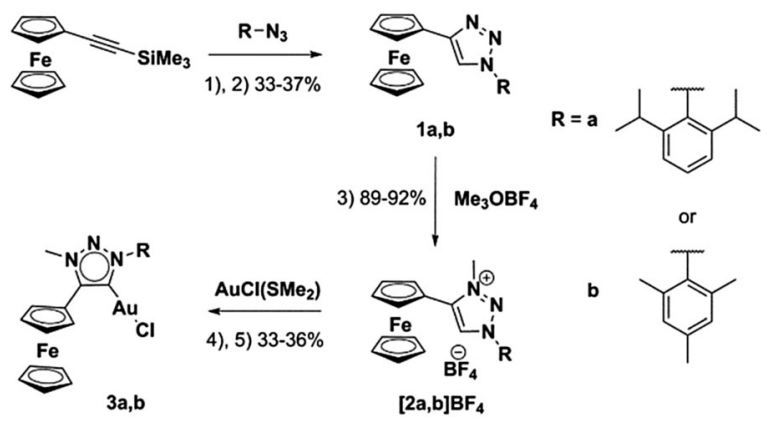

Scheme 1 Preparation of 1-ferrocenyl triazoles, triazolium salts and their $\mathrm{Au}(\mathrm{I})$-carbene-complexes. Conditions: (1) $\mathrm{KF}, \mathrm{MeOH}$, room temperature; (2) $\mathrm{CuSO}_{4} \cdot 5 \mathrm{H}_{2} \mathrm{O}$, sodium ascorbate, TBTA, $\mathrm{H}_{2} \mathrm{O} /{ }^{t} \mathrm{BuOH}, 55^{\circ} \mathrm{C}$; (3) $\mathrm{CH}_{2} \mathrm{Cl}_{2}$, room temperature (4) $\mathrm{Ag}_{2} \mathrm{O}, \mathrm{KCl}, \mathrm{Cs}_{2} \mathrm{CO}_{3}, \mathrm{CH}_{3} \mathrm{CN}$, room temperature; (5) $\mathrm{CH}_{2} \mathrm{Cl}_{2}$, room temperature.

These were then methylated with Meerwein salt to generate triazolium salts $[2 \mathbf{2 a}] \mathrm{BF}_{4}$ and $[2 \mathbf{b}] \mathrm{BF}_{4}$. Transmetallation of $[2 \mathbf{2 a}] \mathrm{BF}_{4}$ and $[2 \mathbf{b}] \mathrm{BF}_{4}$ by reacting them with $\mathrm{Ag}_{2} \mathrm{O}$ followed by their reaction with $\left[\mathrm{Au}\left(\mathrm{SMe}_{2}\right) \mathrm{Cl}\right]$ resulted in the formation of heterobimetallic $\mathrm{Fe}-\mathrm{Au}$ complexes $3 \mathbf{a}$ and $\mathbf{3 b}$ (Scheme 1 and ESI $\dagger$ ).

The formation of the compounds was confirmed by ${ }^{1} \mathrm{H}$ and ${ }^{13} \mathrm{C}$ NMR spectroscopy. The triazole ring $\mathrm{C}-\mathrm{H}$ signal shows up at 7.59 and $7.53 \mathrm{ppm}$ for $\mathbf{1 a}$ and $\mathbf{1 b}$ respectively. Upon methylation of $1 \mathbf{a}$ and $\mathbf{1 b}$ to their corresponding triazolium salts $[\mathbf{2 a}]^{+}$ and $[2 \mathbf{b}]^{+}$these signals shift to 8.53 and $8.52 \mathrm{ppm}$ respectively (see ESI $\dagger$ ). The absence of the ring triazole $\mathrm{C}-\mathrm{H}$ signals in the ${ }^{1} \mathrm{H}$ NMR spectrum of $\mathbf{3 a}$ and $\mathbf{3 b}$ was the first indication for the formation of these carbene complexes. The signal for the carbene-C atom in the ${ }^{13} \mathrm{C}$ spectrum of $\mathbf{3 a}$ and $\mathbf{3 b}$ appears at 161.9 and $160.4 \mathrm{ppm}$ respectively. All compounds were additionally characterized by ESI-MS methods. Molecular peaks corresponding to the mono-protonated forms of $\mathbf{1 a}$ and $\mathbf{1 b}$ were observed in their ESI-MS spectrum. For $[\mathbf{2 a}]^{+}$and $[\mathbf{2 b}]^{+}$the molecular peaks corresponding to the cationic part of the complexes (without $\mathrm{BF}_{4}{ }^{-}$) were detected. Carbene complexes $3 \mathbf{a}$ and $\mathbf{3 b}$ displayed molecular peaks corresponding to cations where the $\mathrm{Cl}^{-}$ligands are lost (see ESI $\dagger$ ). 


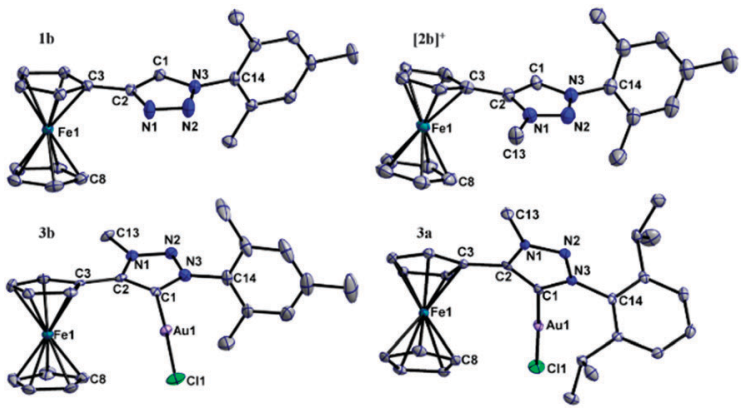

Fig. 1 ORTEP plot of $\mathbf{1 b},[\mathbf{2} \mathbf{b}]^{+}, \mathbf{3} \mathbf{a}$ and $\mathbf{3 b}$. Ellipsoids are drawn at the $50 \%$ probability level. Hydrogen atoms and counter anions have been omitted for clarity.

All the six compounds were also characterized by single crystal X-ray diffraction studies. In ferrocenyl-triazole compounds 1a and 1b, (Fig. 1 and Fig. S24-S25, ESI $\dagger$ ) the central N1-N2 bond distance is shorter compared to the longer N2-N3 and N1-C2 bonds that flank the central bond (Table S7, ESI $\dagger$ ). These data point to bond localization and hence to a predominant "azo" character of the central $\mathrm{N} 1-\mathrm{N} 2$ bond. Upon methylation to $[2 \mathbf{a}] \mathrm{BF}_{4}$ and $[\mathbf{2} \mathbf{b}] \mathrm{BF}_{4}$, the bond distances inside the triazolium ring become more equal indicating a delocalized situation (Table S7, ESI $\dagger$ ). ${ }^{5 d}$ A similar delocalized bonding picture is also observed inside the triazolylidene rings in complexes $\mathbf{3 a}$ and $\mathbf{3 b}$. The $\mathrm{Au}(\mathrm{I})$ centers in $\mathbf{3 a}$ and $\mathbf{3 b}$ are almost linearly coordinated through the MIC-C and the $\mathrm{Cl}^{-}$donors, with the deviation from linearity being between $2^{\circ}$ and $4^{\circ}$. The Au-C(carbene) distances in 3a and $3 \mathbf{b}$ are 1.982(2) and 1.992(5) $\AA$, respectively, and the $\mathrm{Au}-\mathrm{Cl}$ distances in the aforementioned complexes are 2.284(2) and 2.288(2) ̊̊ respectively. The angle around the carbene-C atom becomes smaller upon formation of triazolylidenecomplexes. The mesityl (mes) or the diisopropylphenyl (dipp) substituents in all six compounds are almost perpendicular to the triazole/triazolium/triazolylidene rings (Table S9, ESI $\dagger$ ). The distance between the Fe center and the centroid of the $\mathrm{Cp}$ rings is in the range of $1.65 \AA$. The local symmetry at the ferrocene units is close to $D_{5 \mathrm{~h}}$ with deviations from a perfect eclipsed conformation being between $1^{\circ}$ and $3^{\circ}$. The $\mathrm{Fe}-\mathrm{Au}$ distance is more than $4 \AA$ in both $\mathbf{3 a}$ and $\mathbf{3 b}$.

Each of the compounds displays a reversible one-electron oxidation step (Fig. 2, Fig. S8-S15, ESI $\dagger$ ). The peak-to-peak separations for the redox processes of these steps are in the range $90-140 \mathrm{mV}$, and the high values indicating large reorganization energies associated with electron transfer in these substituted ferrocenes. This is probably linked to the larger twist angles between the Cp rings in the oxidized complex as compared to the native form (Table S9, $\mathrm{ESI} \dagger$ ).

The reversibility, however, was clearly proven through spectroelectrochemical investigations (vide infra). The oxidation potentials of the triazolium salts $[\mathbf{2 a}]^{+}$and $[\mathbf{2} \mathbf{b}]^{+}$are higher compared to triazole compounds $\mathbf{1 a}$ and $\mathbf{1 b}$ due to the positive charges in the cationic salts. $\mathrm{Au}(\mathrm{I})$ complexes $\mathbf{3} \mathbf{a}$ and $\mathbf{3} \mathbf{b}$ have oxidation potentials, the values of which lie between the two classes of compounds discussed above. No reduction waves were detected for ferrocenyl-triazole compounds $\mathbf{1 a}$ and $\mathbf{1} \mathbf{b}$ within the range of the

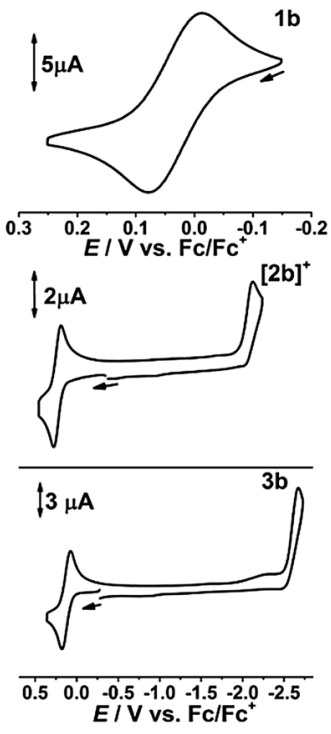

Fig. 2 Cyclic voltammograms of $\mathbf{1 b},[\mathbf{2} \mathbf{b}]^{+}$and $\mathbf{3 b}$ in THF at $100 \mathrm{mV} \mathrm{s}^{-1}$ with $0.1 \mathrm{M} \mathrm{Bu}_{4} \mathrm{NPF}_{6}$ at room temperature.

THF solvent window. In contrast, irreversible reduction steps were observed for the triazolium salts $[2 \mathbf{2}]^{+}$and $[\mathbf{2 b}]^{+}$(Fig. S10 and $\mathrm{S} 11, \mathrm{ESI} \dagger) . \mathrm{Au}(\mathrm{I})$ complexes $\mathbf{3 a}$ and $\mathbf{3 b}$ display irreversible reduction steps at around $-2.8 \mathrm{~V}$ at $298 \mathrm{~K}$. Lowering the temperature to $243 \mathrm{~K}$ led to an improvement in reversibility (Fig. S13 and S15, ESI $\dagger$ ) indicating the involvement of follow-up chemical reactions following reduction in these complexes.

DFT calculations were carried out on $\mathbf{1 b},[\mathbf{2} \mathbf{b}]^{+}$, and $\mathbf{3 b}$ and their oxidized forms as representative examples for the whole series. The bond lengths obtained from the optimized structures show an excellent agreement with the bond lengths obtained from experimental data (Tables S7-S9, ESI $\dagger$ ). A look at the frontier orbitals of Au-triazolylidene complex $\mathbf{3 b}$ shows that the HOMO and HOMO-1 are close in energy ( $\Delta E=0.054 \mathrm{eV}$, Fig. 3) and these are predominantly ferrocenyl-based orbitals. However, the HOMO-2 has strong contributions from $\pi$-type orbitals of triazolylidene (similar to the HOMO-1 calculated for free triazolylidenes), ${ }^{8}$ as well as from gold and chloride based orbitals (Fig. 3). The LUMO of $\mathbf{3 b}$ is almost exclusively based on the triazolylidene ring (and appears similar to the calculated LUMO of free triazolylidenes) ${ }^{8}$ with a small contribution from iron-based orbitals. The HOMO-LUMO gap for $\mathbf{3 b}$ was calculated at $4.096 \mathrm{eV}$.

A comparison of the calculated bond lengths for the oxidized forms with those of the native forms shows that the maximum changes in bond lengths occur within the ferrocenyl ring (for example the Fe-Cp distances, Table S7, ESI + ). The calculated $\mathrm{C}-\mathrm{C} /$ $\mathrm{C}-\mathrm{N} / \mathrm{N}-\mathrm{N}$ bond lengths within the triazole/triazolium/triazolylidene rings are only marginally affected by oxidation. These changes are an indication of the ferrocenyl ring getting most affected through the oxidation step (vide infra). Accordingly, Löwdin spin density calculations showed an almost exclusive localization of the spin density on the ferrocenyl part for the one-electron oxidized forms of all three compounds (Fig. 3, Fig. S31 and S33, ESI†). Thus, these data clearly point to the removal of an electron from a ferrocenyl based orbital on one-electron oxidation. The shape of the LUMOs of 

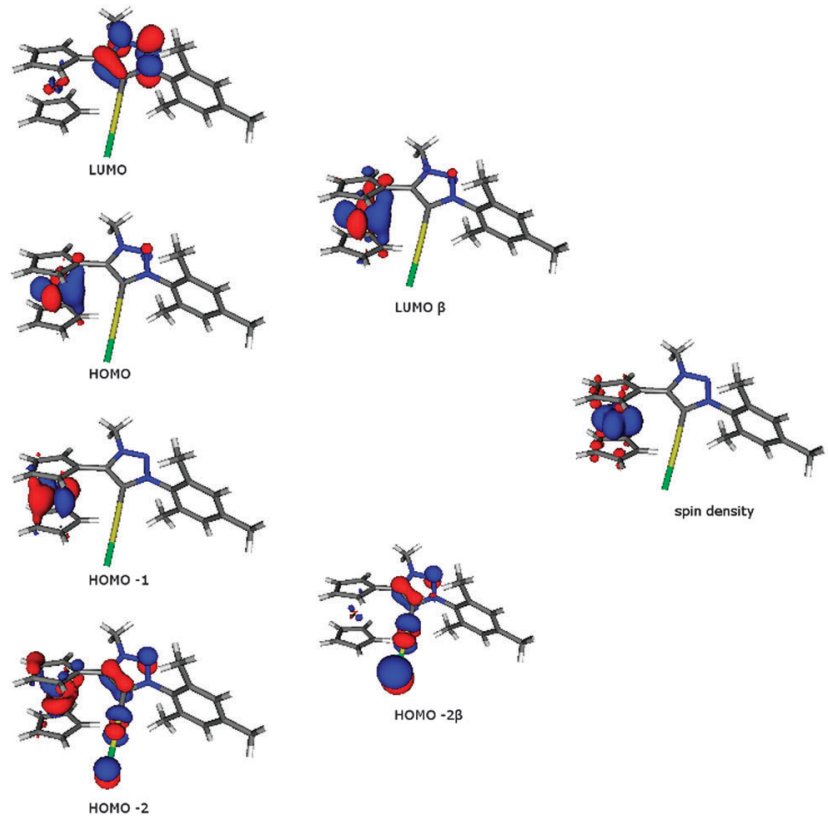

HOMO $-2 \beta$

Fig. 3 Selected calculated frontier orbitals of $\mathbf{3 b}$ (left), orbitals contributing to the long wavelength absorption in $[\mathbf{3 b}]^{\bullet+}$ (middle), Löwdin spin density plot for $[\mathbf{3} \mathbf{b}]^{\bullet+}$.

all compounds, together with the shift in redox potentials mentioned above, also clearly points to a triazolylidene-based reduction, even though we cannot present experimental spectroscopic data for the reduced forms due to the irreversible nature of the reduction steps.

The native state of all compounds shows absorptions predominantly in the UV region. The most intriguing change of the spectrum on one-electron oxidation is the appearance of a weak absorption band at lower energies (Fig. 4). Such a weak band at lower energies is well known for the unsubstituted ferrocenium cation. ${ }^{9}$ For the present case, the position of this band is highly variable, with the band maxima being at $732 \mathrm{~nm}, 643 \mathrm{~nm}$ and $713 \mathrm{~nm}$ for $[\mathbf{1 b}]^{\bullet+},[\mathbf{2 b}]^{\bullet 2+}$ and $[\mathbf{3 b}]^{\bullet+}$ respectively (Fig. 4).

TD-DFT calculations were performed to obtain insights into the UV-vis spectra in the various redox states. These calculations reproduced the positions, intensities, as well as the trend in the positions of the bands with reasonable accuracy (Tables S10-S12, ESI $\dagger)$. For $[\mathbf{1 b}]^{\bullet+}$ the long wavelength band was calculated to have a predominant contribution from HOMO $-2(\beta) \rightarrow \operatorname{LUMO}(\beta)$ (Fig. S30 and Table S10, ESI $\dagger$ ). This band is thus a mixture of ferrocenyl-based transition and triazolylidene $\rightarrow$ ferrocenyl, ligand-to-metal charge transfer (LMCT) transition (as opposed to pure ferrocenyl based transition). For $[2 \mathbf{b}]^{\bullet 2+}$ the long wavelength band was calculated to have contributions from HOMO-2( $\beta) \rightarrow$ LUMO $(\beta)$ and HOMO $-4(\alpha) \rightarrow$ LUMO+1( $\alpha$ ) (Fig. S32 and Table S11, ESI $\dagger$ ) thus also indicating a mixed ferrocenyl based and a LMCT transition. The LMCT contribution to these bands clearly explains their shifts to higher energy on moving from $[\mathbf{1 b}]^{\bullet+}$ to $[\mathbf{2 b}]^{\bullet 2+}$. Placing a positive charge on the triazole ring will energetically stabilize the triazolium-based orbital and increase the energy gap between the triazolium-based orbital and ferrocenyl based orbitals (as compared to the gap between triazole and ferrocenyl orbitals)

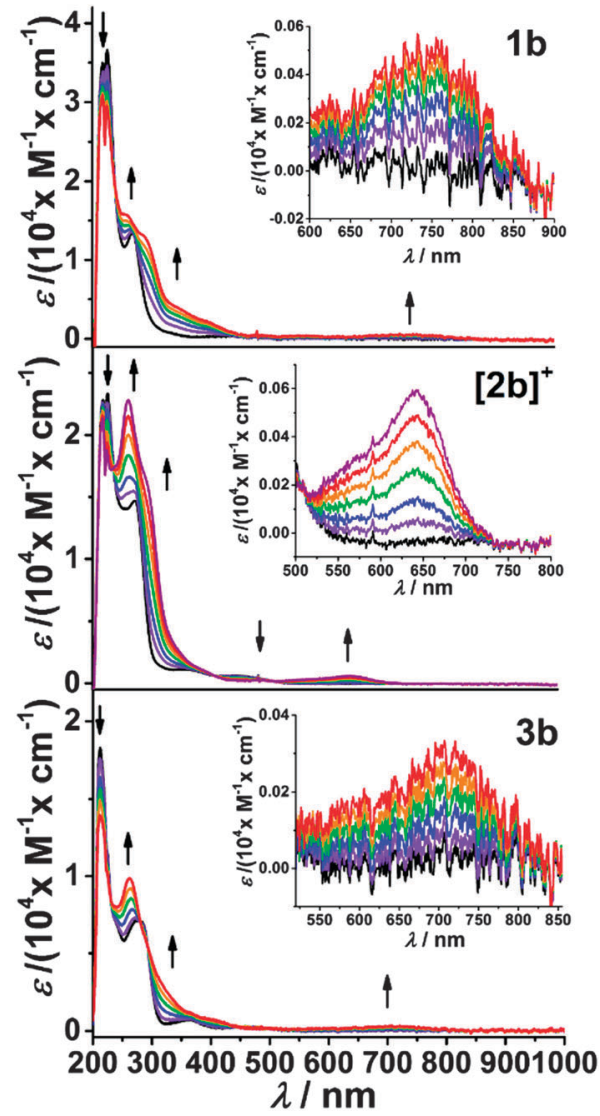

Fig. 4 Changes in the UV/Vis absorption of $\mathbf{1} \mathbf{b},[\mathbf{2} \mathbf{b}]^{+}$and $\mathbf{3 b}$ in the course of a one-electron oxidation in THF/0.1 $\mathrm{M} \mathrm{Bu}_{4} \mathrm{NPF}_{6}$ at room temperature. Insets show a zoom of the long wavelength band.

thus shifting the long wavelength band to higher energies. For $[3 \mathbf{b}]^{\mathbf{e}^{+}}$the predominant contribution to the long wavelength band comes from HOMO $-2(\beta) \rightarrow \operatorname{LUMO}(\beta)$ (Fig. 3 and Table S12, ESI $\dagger$ ). This band can thus be described as a combination of LMCT (triazolylidene to ferrocenyl as well as chloride to ferrocenyl) and gold to ferrocenyl metal-to-metal charge transfer (MMCT) transition with no ferrocenyl-based contributions. MMCT bands are often observed for the one-electron oxidized forms of bimetallic complexes. ${ }^{10}$

The catalytic activity of $\mathrm{Au}(\mathrm{I})$ complexes has often been correlated with the Lewis-acidic nature of the $\mathrm{Au}(\mathrm{I})$ centre. ${ }^{12}$ With this background in mind, we performed the chemical oxidation of $\mathbf{3 b}$ with acetyl-ferrocenyl tetrafluoroborate. An instant colour change of the solution from yellow to green (Fig. S1, ESI $\dagger$ ) indicated the formation of $[\mathbf{3 b}]^{\bullet+}$. The isolated green product was characterized through elemental analyses and by matching its UV-vis-NIR spectrum with that of the electrochemically generated species (Experimental section and Fig. S22 and S23, ESI $\dagger$ ). Oxidation of the ferrocene unit should increase the Lewis acidity of the Au(I) center. Gratifyingly, the cyclization of $N(2-p r o p y n-1-y l)$ benzamide to 5-methylene-2-phenyl-4,5-dihydrooxazole was catalysed by $1 \mathrm{~mol} \%$ of in situ generated $[3 \mathbf{b}]^{0^{+}}$, delivering $40 \%$ conversion after $5 \mathrm{~h}$ and $88 \%$ conversion after $24 \mathrm{~h}$ (Scheme 2, Table S1, ESI $\dagger$ ). Under identical conditions, un-oxidized neutral complex $\mathbf{3 b}$ gave no conversion after $5 \mathrm{~h}$ 


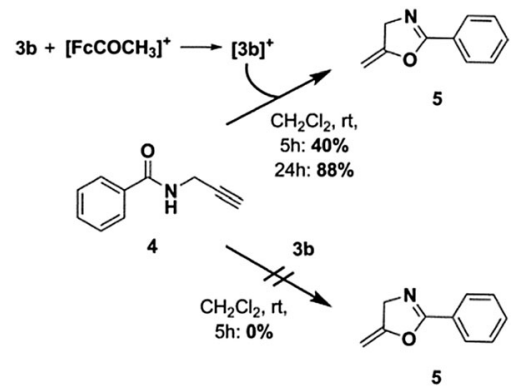

Scheme 2 Oxidation induced Au(I)-catalyzed formation of 4,5-dihydrooxazole.

and only $12 \%$ conversion after $24 \mathrm{~h}$. These results thus clearly prove that oxidation at the ferrocene center can be used to activate an otherwise inactive $\mathrm{Au}(\mathrm{I})$ catalyst towards cyclization reactions.

In summary, we have presented herein the first example of heterobimetallic complexes with ferrocenyl-triazolylidenes as a redox-active metalloligand. The electronic structures of these compounds have been investigated. Redox-induced catalytic activity was seen for the ferrocenyl-Au(I) complexes, proving the importance of the MIC ligand as well as the ferrocenyl centre for such catalytic cyclization reactions. The redox-active, mesoionic carbene based metalloligand presented here will certainly be useful for generating heterobimetallic complexes with a host of other metal centers. Since most applications of metal complexes of mesoionic carbenes have been in homogeneous catalysis, ${ }^{5,6,8,11}$ the incorporation of a redox-active backbone opens up new avenues for these systems. The presence of the electro-active ferrocene unit will likely make these metalloligands useful components for redox-switchable catalysis (first attempts have been shown here) and electro-active materials.

We are grateful to the Fonds der Chemischen Industrie (doctoral stipend for S.M.), the Deutsche Forschungsgemeinschaft (DFG) and the Freie Universität Berlin for financial support of this work. ZEDAT (FU Berlin) is acknowledged for access to their computer cluster.

\section{Notes and references}

1 For a recent review see: G. Kumar and R. Gupta, Chem. Soc. Rev., 2013, 42, 9403.

2 For selected examples and reviews see: (a) G. Bandoli and A. Dolmella, Coord. Chem. Rev., 2000, 209, 161; (b) A. Fihri, P. Meunier and J.-C. Hierso, Coord. Chem. Rev., 2007, 251, 2017; (c) D. A. Young, S. W. Chienb and T. S. Andy Hor, Dalton Trans., 2012, 41, 12655; (d) S. Roy, B. Sarkar, D. Bubrin, M. Niemeyer, S. Zalis, G. K. Lahiri and W. Kaim, J. Am. Chem. Soc., 2008, 130, 15230; (e) P. Braunstein, D. Bubrin and B. Sarkar, Inorg. Chem., 2009, 48, 2534; $(f)$ D. Schweinfurth, N. Büttner, S. Hohloch, N. Deibel, J. Klein and B. Sarkar, Organometallics, 2013, 32, 5834; $(g)$ M. Mohankumar, M. Holler, J.-F. Nierengarten and J.-P. Sauvage, Chem. - Eur. J., 2012, 18, 12192.

3 For selected examples see: (a) B. Bildstein, M. Malaun, H. Kopacka, K.-H. Ongania and K. Wurst, J. Organomet. Chem., 1998, 552, 45; (b) C. K. A. Gregson, V. C. Gibson, N. J. Long, E. L. Marshall, P. J. Oxford and A. J. P. White, J. Am. Chem. Soc., 2006, 128, 7410; (c) M. Süssner and H. Plenio, Angew. Chem., Int. Ed., 2005, 44, 6885; (d) H. Seo, B. Y. Kim, J. H. Lee, H.-J. Park, S. U. Son and
Y. K. Chun, Organometallics, 2003, 22, 4783; (e) A. Dallas, H. Kuhtz, A. Farrell, B. Quilty and K. Nolan, Tetrahedron Lett., 2007, 48, 1017; $(f)$ N. Debono, A. Labande, E. Manoury, J.-C. Daran and R. Poli, Organometallics, 2010, 29, 1879; $(g)$ K. S. Coleman, S. Turberville, S. I. Pascu and M. L. H. Green, J. Organomet. Chem., 2005, 690, 653; (h) K. Arumugam, C. D. Varnado, Jr., S. Sproules, V. M. Lynch and C. W. Bielawski, Chem. - Eur. J., 2013, 19, 10866; (i) U. Siemeling, C. Färber and C. Bruhn, Chem. Commun., 2009, 98; $(j)$ A. Bertogg, F. Camponiva and A. Togni, Eur. J. Inorg. Chem., 2005, 347.

4 For selected reviews see: (a) F. E. Hahn and M. C. Jahnke, Angew. Chem., Int. Ed., 2008, 47, 3122; (b) W. A. Herrmann, Angew. Chem., Int. Ed., 2002, 41, 1290; (c) E. A. B. Kantchev, C. J. O'Brien and M. G. Organ, Angew. Chem., Int. Ed., 2007, 46, 2768; (d) C. C. Loh and D. Enders, Chem. - Eur. J., 2012, 18, 10212; (e) J. D. Egbert, C. S. J. Cazin and S. P. Nolan, Catal. Sci. Technol., 2013, 3, 912.

5 (a) K. F. Donnelly, A. Petronilho and M. Albrecht, Chem. Commun., 2013, 49, 1145; (b) R. H. Crabtree, Coord. Chem. Rev., 2013, 257, 755; (c) J. M. Aizpurua, R. M. Fratila, Z. Monasterio, N. Perez-Esnaola, E. Andreieff, A. Irastorza and M. Sagartzazu-Aizpurua, New J. Chem., 2014, 38, 474; (d) D. Schweinfurth, N. Deibel, F. Weisser and B. Sarkar, Nachr. Chem., 2011, 59, 937; (e) J. D. Crowley, A. Lee and K. J. Kilpin, Aust. J. Chem., 2011, 64, 1118.

6 (a) M. T. Zamora, M. J. Farguson and M. Cowie, Organometallics, 2012, 31, 5384; (b) J. Cai, X. Yang, K. Arumugam, C. W. Bielawski and J. L. Sessler, Organometallics, 2011, 30, 5033; (c) E. C. Keske, O. V. Zenkina, R. Wang and C. M. Crudden, Organometallics, 2012, 31, 456; (d) K. J. Kilpin, U. S. D. Paul, A.-L. Lee and J. D. Crowley, Chem. Commun., 2011, 47, 328; (e) R. Maity, S. Hohloch, M. van der Meer and B. Sarkar, Chem. - Eur. J., 2014, 20, 9952; $(f)$ R. Maity, M. van der Meer and B. Sarkar, Dalton Trans., 2015, 44, 46.

7 For selected examples on ferrocenyl-triazoles see: (a) T. Romero, R. A. Orenes, A. Tarraga and P. Molina, Organometallics, 2013, 32, 5740; (b) S. Badeche, J.-C. Daran and D. Astruc, Inorg. Chem., 2008, 47, 4903; (c) V. S. Sudhir, N. Y. P. Kumar and S. Chandrasekharan, Tetrahedron, 2010, 66, 1327; (d) J. E. M. Lewis, C. J. McAdam, M. G. Gardiner and J. D. Crowley, Chem. Commun., 2013, 49, 3398; (e) B. S. Uppal, A. Zahid and P. I. P. Elliot, Eur. J. Inorg. Chem., 2013, 2571; $(f)$ Q.-Y. Cao, T. Pradhan, S. Kim and J. S. Kim, Org. Lett., 2011, 13, 4386; ( $g$ ) A. J. Salmon, M. L. Williams, Q. K. Wu, J. Morizzi, D. Gregg, S. A. Charman, D. Vullo, C. T. Supuran and S.-A. Poulsen, J. Med. Chem., 2012, 55, 5506; (h) K. Kumar, S. Cerrere-Kremer, L. Kremer, Y. Guerardel, C. Biot and V. Kumar, Inorg. Chem., 2013, 32, 5713; (i) M. Verschoor-Kirss, J. Kreisz, W. Feighery, W. M. Reiff, C. M. Frommen and R. U. Kirss, J. Organomet. Chem., 2009, 694, 3262.

8 J. Bouffard, B. K. Keitz, R. Tonner, G. Guisado-Barrios, G. Frenking, R. H. Grubbs and G. Bertrand, Organometallics, 2011, 30, 2617.

9 (a) R. Prins, Chem. Commun., 1970, 280; (b) U. Pfaff, A. Hildebrandt, D. Schaarschmidt, T. Hahn, S. Liebing, J. Kortus and H. Lang, Organometallics, 2012, 31, 6761.

10 W. Kaim and B. Sarkar, Coord. Chem. Rev., 2007, 251, 584.

11 For selected recent examples see: (a) S. Hohloch, C.-Y. Su and B. Sarkar, Eur. J. Inorg. Chem., 2011, 3067; (b) S. Hohloch, D. Scheiffele and B. Sarkar, Eur. J. Inorg. Chem., 2013, 3956; (c) S. Hohloch, B. Sarkar, L. Nauton, F. Cisnetti and A. Gautier, Tetrahedron Lett., 2013, 54, 1808; (d) S. Hohloch, W. Frey, C.-Y. Su and B. Sarkar, Dalton Trans., 2013, 42, 11355; (e) S. Hohloch, L. Suntrup and B. Sarkar, Organometallics, 2013, 32, 7376; $(f)$ S. Hohloch, L. Hettmanczyk and B. Sarkar, Eur. J. Inorg. Chem., 2014, 3164; $(g)$ A. Bolje, S. Hohloch, D. Urankar, A. Pevec, M. Gazvoda, B. Sarkar and J. Kosmrlj, Organometallics, 2014, 33, 2588; (h) T. Nakamura, T. Terashima, K. Ogata and S. Fukuzawa, Org. Lett., 2011, 13, 620; (i) D. Canseco-Gonzalez, A. Gniewek, M. Szulmanowicz, H. Müller-Bunz, A. M. Trzeciak and M. Albrecht, Chem. - Eur. J., 2012, 18, 6055; $(j)$ J. Huang, J.-T. Hong and S. H. Hong, Eur. J. Org. Chem., 2012, 6630; (k) S. Hohloch, S. Kaiser, F.-L. Duecker, A. Bolje, R. Maity, J. Kosmrlj and B. Sarkar, Dalton Trans., 2015, 44, 686; (l) D. CanescoGonzalez, A. Petronilho, H. Mueller-Bunz, K. Ohmatsu, T. Ooi and M. Albrecht, J. Am. Chem. Soc., 2013, 135, 13193.

12 For a recent review see: R. Dorel and A. M. Echavarren, Chem. Rev., 2015, DOI: 10.1021/cr500691k. 